University of Nebraska - Lincoln

DigitalCommons@University of Nebraska - Lincoln

Faculty Publications from the Department of Electrical \& Computer Engineering, Department Electrical and Computer Engineering

2010

\title{
Hydrogen in InN: A ubiquitous phenomenon in molecular beam epitaxy grown material
}

\author{
V. Darakchieva \\ Instituto Tecnológico e Nuclear, 2686-953 Sacavém, Portugal \\ K. Lorenz \\ Instituto Tecnológico e Nuclear, Sacavém, Portugal \\ N. P. Barradas \\ Instituto Tecnológico e Nuclear, 2686-953 Sacavém, Portugal \\ E. Alves \\ Instituto Tecnológico e Nuclear, 2686-953 Sacavém, Portugal \\ B. Monemar \\ Department of Physics, Chemistry and Biology, Linköping University \\ See next page for additional authors
}

Follow this and additional works at: https://digitalcommons.unl.edu/electricalengineeringfacpub

Part of the Electrical and Computer Engineering Commons

Darakchieva, V.; Lorenz, K.; Barradas, N. P.; Alves, E.; Monemar, B.; Schubert, Mathias; Franco, N.; Hsiao, C. L.; Chen, L. C.; Schaff, W. J.; Tu, L. W.; Yamaguchi, T.; and Nanishi, Y., "Hydrogen in InN: A ubiquitous phenomenon in molecular beam epitaxy grown material" (2010). Faculty Publications from the Department of Electrical and Computer Engineering. 119.

https://digitalcommons.unl.edu/electricalengineeringfacpub/119

This Article is brought to you for free and open access by the Electrical \& Computer Engineering, Department of at DigitalCommons@University of Nebraska - Lincoln. It has been accepted for inclusion in Faculty Publications from the Department of Electrical and Computer Engineering by an authorized administrator of DigitalCommons@University of Nebraska - Lincoln. 


\section{Authors}

V. Darakchieva, K. Lorenz, N. P. Barradas, E. Alves, B. Monemar, Mathias Schubert, N. Franco, C. L. Hsiao, L. C. Chen, W. J. Schaff, L. W. Tu, T. Yamaguchi, and Y. Nanishi 


\title{
Hydrogen in InN: A ubiquitous phenomenon in molecular beam epitaxy grown material
}

\author{
V. Darakchieva, ${ }^{1,2, a)}$ K. Lorenz, ${ }^{1}$ N. P. Barradas, ${ }^{1}$ E. Alves, ${ }^{1}$ B. Monemar, ${ }^{2}$ M. Schubert, ${ }^{3}$ \\ N. Franco ${ }^{1}$ C. L. Hsiao, ${ }^{4}$ L. C. Chen, ${ }^{4}$ W. J. Schaff, ${ }^{5}$ L. W. Tu, ${ }^{6}$ T. Yamaguchi, ${ }^{7}$ and \\ Y. Nanishi ${ }^{3}$ \\ ${ }^{1}$ Instituto Tecnológico e Nuclear, 2686-953 Sacavém, Portugal \\ ${ }^{2}$ Department of Physics, Chemistry and Biology, Linköping University, SE-581 83 Linköping, Sweden \\ ${ }^{3}$ Department of Electrical Engineering, University of Nebraska, Lincoln, Nebraska 68588, USA \\ ${ }^{4}$ Center for Condensed Matter Sciences, National Taiwan University, Taipei 106, Taiwan \\ ${ }^{5}$ Department of Electrical and Computer Engineering, Cornell University, Ithaca, New York 14853, USA \\ ${ }^{6}$ Department of Physics and Center for Nanoscience and Nanotechnology, National Sun Yat-Sen \\ University, Kaohsiung 80424, Taiwan \\ ${ }^{7}$ Department of Photonics, Ritsumeikan University, Shiga 525-8577, Japan
}

(Received 4 January 2010; accepted 28 January 2010; published online 23 February 2010)

\begin{abstract}
We study the unintentional $\mathrm{H}$ impurities in relation to the free electron properties of state-of-the-art InN films grown by molecular beam epitaxy (MBE). Enhanced concentrations of $\mathrm{H}$ are revealed in the near surface regions of the films, indicating postgrowth surface contamination by $\mathrm{H}$. The near surface hydrogen could not be removed upon thermal annealing and may have significant implications for the surface and bulk free electron properties of InN. The bulk free electron concentrations were found to scale with the bulk $\mathrm{H}$ concentrations while no distinct correlation with dislocation density could be inferred, indicating a major role of hydrogen for the unintentional conductivity in MBE InN. (C) 2010 American Institute of Physics. [doi:10.1063/1.3327333]
\end{abstract}

Electronic materials often contain significant concentrations of hydrogen as a result of its ubiquitous nature. Hydrogen strongly affects material properties. In most semiconductors monoatomic hydrogen counteracts the prevailing conductivity. ${ }^{1}$ However, in some III-V materials, e.g., $\mathrm{InN}, \mathrm{InSb}, \mathrm{GaSb}$, or in $\mathrm{ZnO}$ hydrogen acts as a source of doping. ${ }^{1,2}$ A particular case of interest is presented by $\mathrm{InN}$ and In-rich $\mathrm{InGa}(\mathrm{Al}) \mathrm{N}$ alloys, which have significant technological potential in advanced optoelectronic, photovoltaic, and electronic devices. Currently, the most important issues in the field of InN-based materials are to understand the underlying doping mechanism for the intrinsic $n$-type conductivity in the materials and to achieve reliable $p$-type conductivity. Nitrogen vacancies, $V_{\mathrm{N}}$, associated with dislocations, ${ }^{3,4}$ unintentional impurities, such as H (Refs. 2 and 5-9) and $\mathrm{O},{ }^{6,8}$ and complexes of In vacancies with $\mathrm{N}$ on the In-site ${ }^{10}$ have been suggested as possible sources for the unintentional $n$-type doping in $\mathrm{InN}$.

In this letter we study the $\mathrm{H}$ impurities in relation to the unintentional $n$-type conductivity in state-of-the-art $\mathrm{InN}$ films grown by molecular beam epitaxy (MBE). The films with (0001) orientations were grown on sapphire substrate at three growth laboratories: using GaN buffer layers (Cornell University), ${ }^{11} \mathrm{GaN}$ templates (National Sun Yat-Sen University), ${ }^{12}$ or low-temperature (LT) InN buffer layers (Ritsumeikan University). ${ }^{13}$ Details on the samples are given in Table I.

The free electron properties in the films were measured by infrared spectroscopic ellipsometry (IRSE). ${ }^{14,15}$ The IRSE data were analyzed by employing anisotropic dielectric functions of sapphire, InN and GaN in the model calculations. Contributions of the IR active polar phonons to the InN and

\footnotetext{
a) Author to whom correspondence should be addressed. Electronic addresses: vanya@ifm.liu.se and vanya@itn.pt.
}

GaN model dielectric functions were accounted for by a product representation of harmonic oscillator lineshapes with Lorentzian broadening. ${ }^{16}$ The free-carrier contributions were accounted for by the classical Drude model. ${ }^{16}$ All InN films were found to consist of a bulk region, with a lower free electron concentration, $N_{b}$ and a thin surface layer (thickness $d_{s}$ ) with a higher electron charge accumulation concentration, $N_{s}$. The bulk free electron concentrations, $N_{b}$, and the surface electron sheet densities, provided by the product $N_{s} d_{s}$, extracted from the IRSE data analysis are given in Table I.

The presence of unintentional impurities was investigated by $2 \mathrm{MeV}{ }^{4} \mathrm{He}^{+}$elastic recoil detection analysis (ERDA). The ERDA provides an absolute measurement of impurity concentrations and depth profiles without the need of standards. ${ }^{17}$ The essence of the method is to knock hydrogen atoms out of the target with the mega-electron-volt beam in grazing incidence and to measure the energy spectrum of the $\mathrm{H}$ atoms recoiled from different depths in order to obtain the hydrogen concentration profile in the sample. The lower the energy of the recoiled $\mathrm{H}$ atoms the deeper their original location in the sample. Figure 1(a) shows representative experimental ERDA spectra for three of the samples. A significant enhancement of the $\mathrm{H}$ concentration is observed at high energies, i.e., in the near-surface regions of all films [Fig. 1(a)]. In order to obtain the $\mathrm{H}$ concentrations in the films all ERDA data were fitted with the NDF code using background correction models for double scattering and pile-up. ${ }^{18}$ The fits to the experimental data are shown with solid lines in Fig. 1(a). All samples were measured in five sample spots to improve the accuracy of the results. The averaged surface $\mathrm{H}$ area densities $\left(\mathrm{H}\right.$ atoms $/ \mathrm{cm}^{2}$ ) and bulk $\mathrm{H}$ concentrations $\left(\mathrm{H}\right.$ atoms $\left./ \mathrm{cm}^{3}\right)$ extracted from the fits, and the respective standard errors of the mean are listed in Table I. The respective $\mathrm{H}$ depth profiles obtained from the experimental data are 
TABLE I. Summary of sample structures, free electron properties, $\mathrm{H}$ impurity levels measured by ERDA and densities of edge type dislocations measured by XRD: $d$-film thickness, $N_{s} d_{s}$-sheet surface electron density, $H_{s}^{\text {tot }}$-surface areal density of $H, N_{b}$-bulk free electron concentration, $H_{b}$-bulk $\mathrm{H}$ concentration, $D_{e}$-density of edge type dislocations, SR-RMS surface roughness measured from $5 \times 5 \mu \mathrm{m}^{2}$ atomic force microscopy scans.

\begin{tabular}{|c|c|c|c|c|c|c|c|c|}
\hline Sample: Buffer & Polarity & $\begin{array}{c}d \\
(\mu \mathrm{m})\end{array}$ & $\begin{array}{c}N_{s} d_{s} \\
\left(10^{13} \mathrm{~cm}^{-2}\right)\end{array}$ & $\begin{array}{c}H_{s}^{\text {tot }} \\
\left(10^{16} \mathrm{~cm}^{-2}\right)\end{array}$ & $\begin{array}{c}N_{b} \\
\left(10^{18} \mathrm{~cm}^{-3}\right)\end{array}$ & $\begin{array}{c}H_{b} \\
\left(10^{20} \mathrm{~cm}^{-3}\right)\end{array}$ & $\begin{array}{c}D_{e} \\
\left(10^{10} \mathrm{~cm}^{-2}\right)\end{array}$ & $\begin{array}{c}\text { SR } \\
(\mathrm{nm})\end{array}$ \\
\hline A: MBE GaN/AlN ${ }^{\mathrm{a}}$ & In & 1.60 & $1.0 \pm 0.7$ & $4.5 \pm 0.3$ & $0.19 \pm 0.03$ & $6.0 \pm 0.8$ & 3.5 & 7.4 \\
\hline B: MOVPE $\mathrm{GaN}^{\mathrm{b}}$ & In & 1.27 & $26.8 \pm 6.1$ & $2.7 \pm 0.1$ & $4.33 \pm 0.03$ & $1.5 \pm 0.3$ & 2.8 & 3.0 \\
\hline $\mathrm{C}: \mathrm{MBE} \mathrm{GaN}^{\mathrm{b}}$ & $\mathrm{N}$ & 1.28 & $0.3 \pm 0.1$ & $3.2 \pm 0.5$ & $4.71 \pm 0.03$ & $2.2 \pm 0.4$ & 2.3 & 3.4 \\
\hline D: LT $\operatorname{InN}^{\mathrm{c}}$ & $\mathrm{N}$ & 0.36 & $2.1 \pm 0.2$ & $5.0 \pm 0.9$ & $5.75 \pm 0.03$ & $2.3 \pm 0.6$ & 7.1 & 5.2 \\
\hline E: LT $\operatorname{InN}^{\mathrm{c}}$ & $\mathrm{N}$ & 0.42 & $0.5 \pm 0.1$ & $9.3 \pm 2.8$ & $7.06 \pm 0.03$ & $2.9 \pm 0.8$ & 4.6 & 4.6 \\
\hline
\end{tabular}

${ }^{\mathrm{a}}$ Reference 11 .

${ }^{\mathrm{b}}$ Reference 12.

${ }^{\mathrm{c}}$ Reference 13.

shown in Fig. 1(b). Due to the limited depth resolution of the technique $(\sim 25 \mathrm{~nm})$ the $\mathrm{H}$ depth profiles [Fig. 1(b)] represent the lower limit of the surface $\mathrm{H}$ concentration and the higher limit for the thickness of the near-surface region. The resolution also affects the shape of the extracted profiles causing the apparent increase of $\mathrm{H}$ concentration in the first $10 \mathrm{~nm}$ from the surface in Fig. 1(b). Therefore, in the following we will discuss the total amount of $\mathrm{H}$ in the near surface region (areal density), which is independent of the depth resolution.

The very large $\mathrm{H}$ concentrations measured in the surface regions of our InN films indicate that most probably a surface $\mathrm{H}$ contamination occurs after growth as a result of the samples exposure to ambient atmosphere. We have also performed annealing experiments on the InN films in $\mathrm{N}_{2}$ ambient and in vacuum $\left(10^{-6} \mathrm{mbar}\right)$ at $300-350^{\circ} \mathrm{C}$ for 1 to $15 \mathrm{~h}$. We found that it was not possible to remove the near surface $\mathrm{H}$ upon annealing and its areal density although decreasing remained in the low $10^{16} \mathrm{~cm}^{-2}$ range. The bulk $\mathrm{H}$ concentration in the annealed films decreased only marginally suggesting that there is no significant outdiffussion from the bulk during the annealing. These findings indicate that a significant amount of the $\mathrm{H}$ in the near surface region of $\mathrm{InN}$ is tightly bound to the lattice. A persistent presence of near surface hydrogen $\left(1.5 \times 10^{16} \mathrm{~cm}^{-2}\right)$ has been previously reported for GaN even after in situ sputtering and annealing ${ }^{19}$ and it is a common problem in many material systems. ${ }^{17}$ More recently, postgrowth surface contamination by $\mathrm{H}$ $(0.8-6$ at. \%) has been reported for MBE AlGaN/GaN heterostructures. ${ }^{20}$ Unlike in the rest of the group-III nitrides, $\mathrm{H}$ in InN acts as a source of doping. ${ }^{1,2}$ Therefore, the substantial amount of $\mathrm{H}$ in the near-surface regions of MBE $\mathrm{InN}$
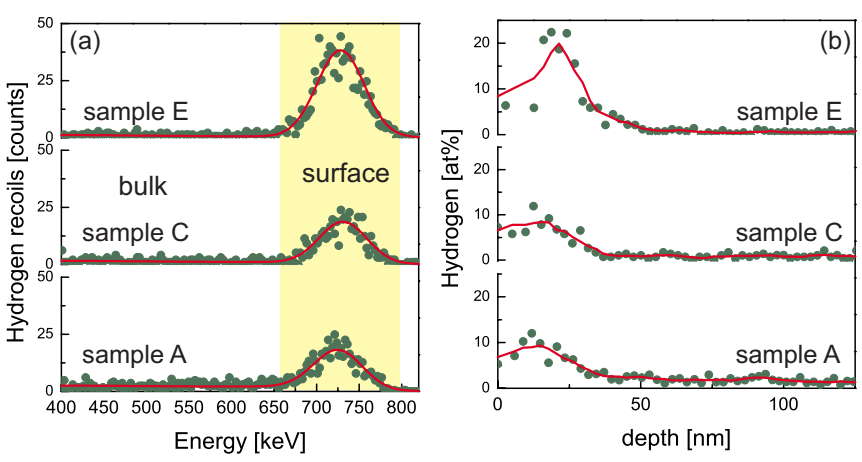

FIG. 1. (Color online) (a) Experimental (symbols) and fitted (lines) ERDA hydrogen spectra; and (b) hydrogen depth profiles extracted from the data of three representative samples. films has very important implications for the material properties. First, the near-surface reservoir of $\mathrm{H}$ could supply $\mathrm{H}$ to the bulk through different diffusion paths during processing and device operation. Note that first principle calculations showed that $\mathrm{H}^{+}$interstitial defects are mobile already at modest temperatures of $\sim 100{ }^{\circ} \mathrm{C}$ when incorporated in defect-free InN. ${ }^{2}$ The high defect densities, typical for InN could facilitate $\mathrm{H}$ diffusion into the bulk even at lower temperatures. Postgrowth $\mathrm{H}$ incorporation into the bulk (up to 0.24 at. \%) via diffusion from the surface through defects (at room temperature) has also been suggested for $\mathrm{MBE}$ $\mathrm{AlGaN} / \mathrm{GaN} .{ }^{20}$ If $\mathrm{H}$ diffuses from the surface into the bulk of $\mathrm{InN}$, the postgrowth $\mathrm{H}$ will add to any $\mathrm{H}$ incorporated during growth. Many factors, like polarity, surface roughness, defect type, and density will affect the overall process. We found a higher amount of surface $\mathrm{H}$ in films with rougher and more irregular surface morphology (Table I: films A, D, and E; see also Ref. 14) compared to the smoother films (Table I: films $\mathrm{B}$ and C; see also Ref. 14). We also observed some lateral variation of the $\mathrm{H}$ content and outdiffusion during the irradiation with the analyzing beam. Our results on InN films with different polarities grown in the same growth reactor and having similar sample histories (Table I: films B and C) indicate similar levels of $\mathrm{H}$ in the samples.

The second important implication of the enhanced $\mathrm{H}$ concentration in the near-surface region is the expected effect on the surface electron properties. The large amount of $\mathrm{H}$ impurities at the surface will play a role for the surface states formation and may alter significantly the band gap renormalization in the near surface region. It seems that the films with higher density of near-surface $\mathrm{H}$ exhibit lower sheet surface electron densities (Table I). However, more work is required to clarify this issue and establish an explicit relationship between the sheet surface electron densities and the surface areal $\mathrm{H}$ densities.

Figure 2 shows the bulk electron concentration versus bulk $\mathrm{H}$ concentration in the films revealing a linear correlation for four of the InN films. The InN film A with the lowest bulk electron concentration, which does not follow the linear trend in Fig. 2 is found to contain $\mathrm{C}$ in the bulk of about 1.0 at. \% ${ }^{14} \mathrm{C}$ may form complexes with $\mathrm{H}$ passivating the $\mathrm{H}$ donors and explaining the low free electron concentration in this case. ${ }^{14}$ In all films the bulk $\mathrm{H}$ concentrations exceed substantially the bulk electron concentrations (Table I), indicating that part of the incorporated $\mathrm{H}$ is in electrically inactive form. $\mathrm{H}$ concentrations exceeding the free electron concentrations have been very recently reported for MBE InN films with In polarity and $N_{b}$ between $1 \times 10^{17}$ and 5 


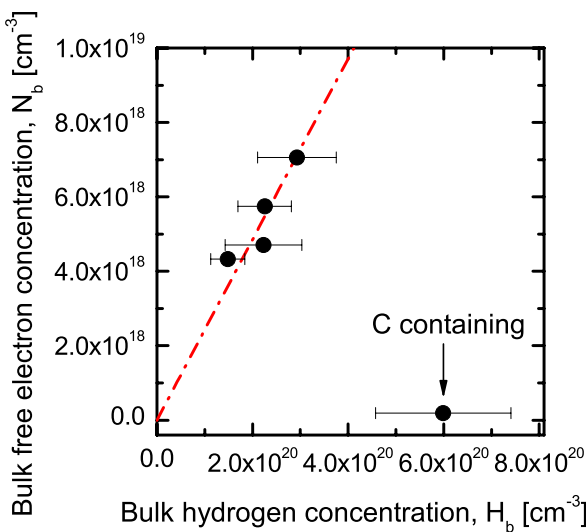

FIG. 2. (Color online) Bulk electron concentration, $N_{b}$ vs bulk $\mathrm{H}$ concentration, $H_{b}$.

$\times 10^{17} \mathrm{~cm}^{-3}{ }^{8}$. The same work also concluded on the major role of $\mathrm{H}$ for the unintentional $n$-type conductivity of such InN films grown by MBE.

We also estimated the density of threading dislocations in our films. The dominant dislocations in $c$-plane InN films is of edge type. ${ }^{21}$ We have estimated the density of edge type dislocations from $\mathrm{x}$-ray diffraction (XRD) rocking curves measured at different inclination angles and the extrapolated twist at inclination of $90^{\circ}$ (Ref. 22) and using a Burgers vector of $0.3539 \mathrm{~nm}^{23}$ The estimated densities, $D_{e}$ are given in Table I and $N_{b}$ is plotted versus $D_{e}$ in Fig. 3. We have confirmed the results for the XRD dislocation densities by transmission electron microscopy for several representative samples. ${ }^{14}$ No distinct correlation between bulk electron concentration and dislocation density could be inferred from Fig. 3 . This result is in agreement with our previous findings from Optical Hall effect measurements for a series of $c$-plane $\mathrm{InN}$ films of doping mechanism unrelated to dislocations. ${ }^{7}$ The measured high bulk $\mathrm{H}$ concentrations that scales with the free electron concentrations (Fig. 2) indicate $\mathrm{H}$ as the plausible source for the unintentional conductivity in the $\mathrm{InN}$ films.

In summary, we studied the unintentional $\mathrm{H}$ impurity concentrations and depth profiles in state-of-the-art MBE InN films by elastic recoil detection analysis. Enhanced concentrations of $\mathrm{H}$ are revealed in the near surface regions of the films indicating postgrowth surface contamination by $\mathrm{H}$ that could not be removed upon thermal annealing. The near

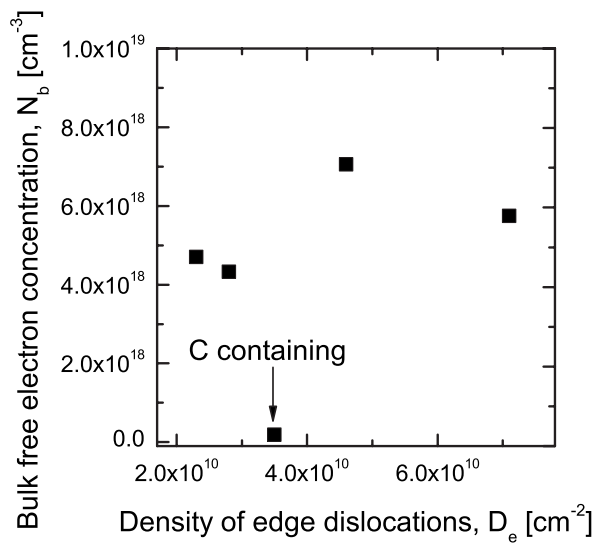

FIG. 3. Bulk electron concentration, $N_{b}$ vs density of edge type dislocations, $D_{e}$. surface $\mathrm{H}$ may have significant implications for the surface electron properties of $\mathrm{InN}$ and serve as reservoir for codoping the bulk. Significant concentrations of bulk H, scaling with the bulk free electron concentrations are measured in films grown at different growth laboratories indicating that $\mathrm{H}$ plays a major role for the unintentional $n$-type conductivity in MBE InN.

This work is financially supported by FCT Portugal under Contract No. PTDC/FIS/100448/2008 and program Ciência 2007. We acknowledge support from the Swedish Research Council (VR) under Grant No. 2005-5054. Financial support from NSF MRSEC (Grant No. DMR-0820521), U.S. Army Research Office (Grant No. W911NF-08-C-0111), and J. A. Woollam Foundation is acknowledged.

${ }^{1}$ C. G. Van de Walle and J. Neugebauer, Annu. Rev. Mater. Res. 36, 179 (2006).

${ }^{2}$ A. Janotti and C. G. Van de Walle, Appl. Phys. Lett. 92, 032104 (2008).

${ }^{3}$ V. Cimalla, V. Lebedev, F. M. Morales, R. Goldhahn, and O. Ambacher, Appl. Phys. Lett. 89, 172109 (2006).

${ }^{4}$ L. F. J. Piper, T. D. Veal, C. F. McConville, H. Lu, and W. J. Schaff, Appl. Phys. Lett. 88, 252109 (2006).

${ }^{5}$ D. C. Look, H. Lu, W. Schaff, J. Jasinski, and Z. Liliental-Weber, Appl. Phys. Lett. 80, 258 (2002).

${ }^{6}$ C. S. Gallinat, G. Koblmüller, J. S. Brown, S. Bernardis, J. S. Speck, G. D. Chern, E. D. Readinger, H. Shen, and M. Wraback, Appl. Phys. Lett. 89, 032109 (2006).

${ }^{7}$ V. Darakchieva, T. Hofmann, M. Schubert, B. E. Sernelius, B. Monemar, P. O. Å. Persson, F. Giuliani, E. Alves, H. Lu, and W. J. Schaff, Appl. Phys. Lett. 94, 022109 (2009).

${ }^{8}$ C. S. Gallinat, G. Koblmüller, and J. S. Speck, Appl. Phys. Lett. 95, 022103 (2009).

${ }^{9}$ S. Ruffenach, M. Moret, O. Briot, and B. Gil, Appl. Phys. Lett. 95, 042102 (2009).

${ }^{10}$ K. S. A. Butcher, A. J. Fernandes, P. P.-T. Chen, M. Winterbert-Fouquet, H. Timmers, S. K. Shrestha, H. Hirshy, R. M. Perks, and B. F. Usher, J. Appl. Phys. 101, 123702 (2007).

${ }^{11}$ H. Lu, W. J. Schaff, J. Hwang, H. Wu, G. Koley, and L. F. Eastman, Appl. Phys. Lett. 79, 1489 (2001).

${ }^{12}$ C.-H. Liang, Z. H. Sun, C. L. Hsiao, Z. M. Hsu, L. W. Tu, J.-Y. Lin, L. C. Chen, J. H. Chen, Y. F. Chen, and C. T. Wu, Appl. Phys. Lett. 90, 172101 (2007).

${ }^{13}$ Y. Nanishi, Y. Saito, T. Yamaguchi, M. Hori, F. Matsuda, T. Araki, A. Suzuki, and T. Miyajima, Phys. Status Solidi A 200, 202 (2003).

${ }^{14}$ V. Darakchieva, N. P. Barradas, M.-Y. Xie, K. Lorenz, E. Alves, M. Schubert, P. O. Å. Persson, F. Giuliani, F. Munnik, C. L. Hsiao, L. W. Tu, and W. J. Schaff, Physica B 404, 4476 (2009).

${ }^{15}$ V. Darakchieva, M. Schubert, T. Hofmann, B. Monemar, C. L. Hsiao, T. W. Liu, L. C. Chen, W. J. Schaff, Y. Takagi, and Y. Nanishi, Appl. Phys. Lett. 95, 202103 (2009).

${ }^{16}$ V. Darakchieva, T. Paskova, M. Schubert, H. Arwin, P. P. Paskov, B. Monemar, D. Hommel, M. Heuken, J. Off, F. Scholz, B. A. Haskell, P. T. Fini, J. S. Speck, and S. Nakamura, Phys. Rev. B 75, 195217 (2007).

${ }^{17}$ A. D. Marwick, in Semiconductors and Semimetals, edited by J. I. Pankove and N. M. Johnson (Academic, San Diego, 1991), Vol. 34, p. 185.

${ }^{18}$ N. P. Barradas, C. Jeynes, and R. P. Webb, Appl. Phys. Lett. 71, 291 (1997).

${ }^{19}$ M. M. Sung, J. Ahn, J. W. Rabalais, D. D. Koleske, and A. E. Wickenden, Phys. Rev. B 54, 14652 (1996).

${ }^{20}$ F. G. González-Posada Flores, A. Redondo-Cubero, R. Gago, A. Bengoechea, A. Jiménez, D. Grambole, A. F. Braña, and E. Muñoz, J. Phys. D 42, 055406 (2009).

${ }^{21}$ H. Lu, W. J. Schaff, L. F. Eastman, and C. E. Stutz, Appl. Phys. Lett. 82, 1736 (2003)

${ }^{22}$ V. Srikant, J. S. Speck, and D. R. Clarke, J. Appl. Phys. 82, 4286 (1997)

${ }^{23}$ V. Darakchieva, M.-Y. Xie, F. Tasnádi, I. A. Abrikosov, L. Hultman, B. Monemar, J. Kamimura, and K. Kishino, Appl. Phys. Lett. 93, 261908 (2008). 